\title{
PENGARUH DISIPLIN DAN KOMPETENSI DOSEN TERHADAP PRESTASI MAHASISWA PROGRAM STUDI PENERBITAN
}

\author{
Benget Simamora \\ Program Studi Penerbitan, Jurusan Penerbitan, \\ Politeknik Negeri Media Kreatif Jakarta
}

\begin{abstract}
:
The purpose of this study is to analyze how much the independent variables of discipline and competence of lecturer influence on student achievement Publishing department Creative Media State Polytechnic of Jakarta, either partially or simultaneously. Research subjects were 68 students. Each questionnaire consists of 15 questions for each study variable discipline, competence, and student achievement. To determine the influence of independent variables of discipline and competence on student achievement is determined by the regression equation, both multiple regression and simple regression. To determine the significance, the data obtained from the questionnaire was tested its validity through the validity, reliability, and test for normality. The data processing using SPSS software version 14. The results showed that (1) discipline positive and significant impact on student achievement with 99\% accuracy, (2) the competence of lecturers positive and significant impact on student achievement with 99\% accuracy, (3) discipline and competence of lecturer together positive and significant impact on achievement student with $95 \%$ accuracy.
\end{abstract}

Keywords: discipline, competence, student achievement.

\section{PENDAHULUAN}

Selama ini penilaian untuk setiap dosen pada umumnya baik dan tidak ada yang kurang baik, walaupun kenyataan di lapangan masih ada dosen yang datang terlambat. Disiplin dosen Politeknik Negeri Media Kreatif Jurusan Penerbitan perlu ditingkatkan untuk meningkatkan prestasi mahasiswa.

Untuk mengukur kedisiplinan sebuah organisasi dapat dilihat berdasarkan beberapa kriteria, antara lain: tingkat produktivitas, efisiensi, motivasi, prestasi kerja, tingkat kecelakaan, pertumbuhan, kontrol, stabilitas, kepuasan dan fleksibilitas.

Semakin banyak kriteria positif yang dimiliki maka sebuah organisasi akan memiliki dosen yang memiliki jiwa disiplin yang tinggi dan tujuan organisasi akan tercapai. Selain kedisiplinan, pembinaan kompetensi dosen harus diadakan agar menghasilkan lulusan yang berkompeten pula.

Upaya untuk meningkatkan kualitas dosen dimulai sejak proses rekrutmen, perbaikan terhadap sistem penempatan, dan pengangkatan dalam jabatan agar 
pegawai ditempatkan pada jabatan yang benar-benar sesuai dengan kompetensi yang dimilikinya.

Berdasarkan permasalahan tersebut, penelitian ini menjadi penting karena menyangkut disiplin dan kompetensi dosen yang berpengaruh terhadap prestasi mahasiswa Politeknik Negeri Media Kreatif Jurusan Penerbitan.

Disiplin menurut Kamus Besar Bahasa Indonesia (2000) berarti "ketaatan (kepatuhan) kepada tata tertib dan sebagainya". Sementara itu, (Moenir, 2000: 181) mengemukakan bahwa yang dimaksud dengan disiplin adalah usaha yang dilakukan untuk menciptakan keadaan di suatu lingkungan kerja yang tertib, berdaya guna dan berhasil guna melalui suatu sistem yang tepat.

Lebih lanjut (Moenir, 2000: 181) mengutip Prayudi Atmosudirjo mengatakan bahwa "Disiplin adalah ketaatan yang sifatnya impersonal, tidak memakai perasaan dan tidak memakai perhitungan pamrih atau kepentingan pribadi. Disiplin adalah satu-satunya jalan atau sarana untuk mempertahankan adanya atau eksistensi daripada organisasi”.

Kemudian, (Nitisesmito, 2001: 118), menyatakan bahwa kedisiplinan dapat diartikan sebagai suatu sikap, tingkah laku dan perbuatan yang sesuai dengan peraturan organisasi, baik yang tertulis maupun lisan.

Berdasarkan

pendapat-

pendapat itu, dapat dikemukakan bahwa disiplin sangat erat berkaitan dengan sikap dan perilaku serta perbuatan yang dilandasi dengan kesadaran untuk menaati semua ketentuan atau peraturan dalam organisasi, baik tertulis maupun tidak tertulis.

Secara umum konsep kompetensi sudah mulai dibicarakan sejak lama dan pada saat itu timbul berbagai pengertian dan definisi tentang kompetensi. Hornby dan Thomas (Prihadi, 2004: 89) mendefinisikan kompetensi sebagai pengetahuan, keterampilan dan kualitas-kualitas manajer atau leader yang efektif. Sementara itu konferensi pakar SDM di Johannesburg (Prihadi, 2004: 91) mengartikan kompetensi sebagai berikut:

"A cluster of related knowledge, skills and attitudes that effects a major part of one's job (role or responsibility) that correlates with performance on the job, that can be measured against well accepted standards, and that can be improved via training and development".

Artinya, kompetensi merupakan seperangkat pengetahuan, keterampilan dan sikap yang saling terkait yang memperngaruhi jabatan yang diduduki seseorang (peran dan tanggung jawab), berkolerasi dengan kinerja pada jabatan tersebut, dan dapat diukur dengan standar-satandar yang diterima serta dapat ditingkatkan melalui upaya-upaya pelatihan dan pengembangan.

Tate (Pribadi, 2004: 90) mendefinisikan kompetensi sebagai: 
"A competence is external to the person; it is what he or she demonstrates in a job". Maksudnya suatu kompetensi adalah sesuatu yang eksternal, yaitu apa yang ditunjukkan seseorang dalam suatu jabatan.

Sementara itu, Lucia dan Lepsiger (Prihadi, 2004: 91) mendefinisikan kompetensi sebagai berikut:

"A competency is builth on the foundation of inherent talent incorporation the types of skill and knowledge that can be acqutted through learning, effort and experience the all innate and acquitted abilities manifest in a specific set of behavoirs".

Artinya, suatu kompetensi dibangun berdasarkan bakat-bakat yang melekat dan berhubungan erat dengan tipe-tipe kemampuan dan pengetahuan yang dapat diperoleh melalui pembelajaran, upaya-upaya pengalaman, semua kemampuan yang dimiliki dan diperolehnya tergambar dari rangkaian tingkah laku yang spesifik. Dengan demikian kompetensi merupakan bagian dari kepribadian seseorang yang cukup dalam dan bersifat permanen.

Prestasi akademis merupakan hasil kerja seseorang mahasiswa selama periode tertentu dibandingkan dengan berbagai kemungkinan misalnya standar, target/sasaran atau kriteria yang telah ditentukan terlebih dahulu dan disepakati bersama. Mangkunegara (2000) menyatakan bahwa prestasi akademik adalah hasil kerja secara kualitas dan kuantitas yang dicapai oleh seseorang mahasiswa dalam melaksanakan tugasnya sesuai dengan tanggung jawab yang diberikan kepadanya.

Hasibuan (2005) menyatakan bahwa prestasi akademik adalah suatu hasil kerja yang dicapai mahasiswa dalam melaksanakan tugas-tugas yang dibebankan kepadanya yang didasarkan atas kecakapan, pengalaman, dan kesungguhan serta waktu. Sementara itu, Sastrohadiwiryo (2002) menyatakan bahwa prestasi akademik adalah kinerja yang dicapai oleh mahasiswa dalam melaksanakan tugas dan pekerjaan yang diberikan kepadanya.

Berdasarkan beberapa pendapat tersebut, dapat disimpulkan bahwa prestasi akademis merupakan hasil yang dicapai mahasiswa dalam pelaksanaan suatu pekerjaan yang diberikan kepadanya baik secara kuantitas maupun kualitas melalui prosedur yang berfokus pada tujuan yang hendak dicapai serta dengan terpenuhinya standar pelaksanaan.

Dalam penelitian ini, hubungan antara variabel bebas yakni Disiplin Dosen $\left(\mathrm{X}_{1}\right)$ dan Kompetensi Dosen $\left(\mathrm{X}_{2}\right)$ sedangkan Prestasi Mahasiswa (Y) sebagai variabel terikat. 


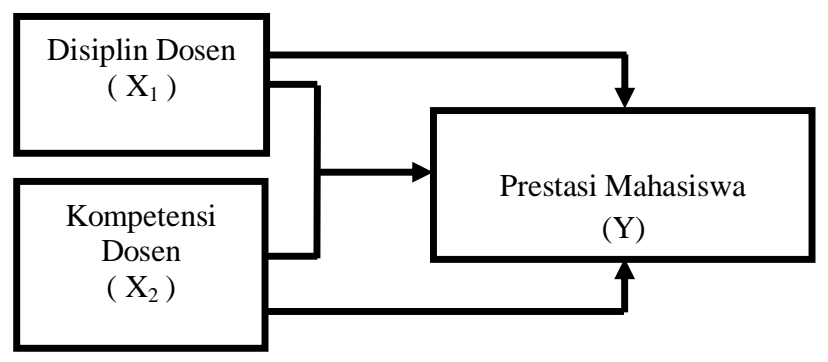

Gambar 1. Kerangka Konseptual

\section{METODE PENELITIAN}

Penelitian ini merupakan Penelitian Deskriptif (Descriptive Research) yang bertujuan untuk mendeskripsikan atau menggambarkan fenomena pengaruh antara dimensi-dimensi dari disiplin dan kompetensi dosen baik secara bersama-sama maupun parsial terhadap prestasi mahasiswa.

Untuk menentukan pengaruh variabel bebas terhadap variabel terikat dilihat dari hasil kuesioner dengan menggunakan skala likert terhadap respon mahasiswa. Hasil angket ini akan ditentukan persamaan regresinya, baik regresi ganda maupun regresi sederhana setelah dilakukan uji validitas, uji reliabilitas, dan uji normalitas dari skor hasil angket.

Subjek penelitian ini adalah mahasiswa program studi Penerbitan Politeknik Negeri Media Kreatif Jakarta. Jumlah populasi penelitian ini sebanyak 212 orang namun yang menjadi sampel 68 orang dengan pertimbangan keterbatasan waktu dan sumber daya penelitian. Pemilihan sampel dilakukan secara random sampling.
Penelitian ini menggunakan data primer yang dikumpulkan melalui survei dengan instrumen penelitian berupa kuesioner. Instrumen pengumpulan data disusun dalam bentuk skala likert dengan indikator sebagai berikut: apabila jawaban Sangat Setuju (SS) diberi nilai 5, apabila jawaban Setuju (S) diberi nilai 4, apabila jawaban Netral (N) diberi nilai 3, apabila jawaban Tidak Setuju (TS) diberi nilai 2, dan apabila jawaban Sangat Tidak Setuju (STS) diberi nilai 1 tetapi sebaliknya jika pada/dengan pertanyaan negatif, maka skor pada $(\mathrm{SS})=1,(\mathrm{~S})=2,(\mathrm{~N})=3, \quad(\mathrm{TS})=4$ dan $(\mathrm{STS})=5$.

Untuk menguji validitas, metode yang dapat digunakan adalah dengan mengkorelasikan setiap butirbutir pertanyaan dengan skor pertanyaan secara keseluruhan. Suatu butir pertanyaan dikatakan valid jika nilai koefisien korelasi pearson $\left(r_{\text {hitung }}\right)$ lebih besar daripada $r_{\text {tabel }}$. Jika $\quad r_{\text {hitung }}>r_{\text {tabel }}$ maka pertanyaan dinyatakan valid dan jika berlaku hal sebaliknya pertanyaan dinyatakan tidak valid dan tidak diikutsertakan pada perhitungan selanjutnya sedangkan untuk mengukur 
reliabilitas dengan menggunakan rumus Cronbach Alpha. Suatu instrumen dikatakan reliabel jika nilai reliabilitas $>0,700$.

Sementara itu, untuk mendeteksi normal tidaknya suatu data variabel dapat menggunakan rumus Kolmogorov-Smirnov $(K-S)$. Aturan untuk menetapkan kenormalan suatu data adalah data dikatakan terdistribusi normal jika nilai Asymp. Sig. (2-tailed) pada output SPSS lebih besar dari level of signifikan (0.05), sebaliknya data dikatakan tidak terdistribusi normal dan data penelitian harus diulang kembali.

\section{HASIL DAN PEMBAHASAN}

\section{Hasil}

\section{Variabel Disiplin Dosen $\left(\mathbf{X}_{1}\right)$}

Berdasarkan hasil pengumpulan data melalui kuesioner, variabel Disiplin Dosen $\left(\mathrm{X}_{1}\right)$ sebagai salah satu faktor yang berpengaruh terhadap Prestasi Mahasiswa memiliki olahan statistik sebagai berikut:

Tabel 4.1 Statistik Variabel Disiplin Dosen $\left(\mathrm{X}_{1}\right)$

\section{Statistics}

skor_X1

\begin{tabular}{|l|l|r|}
\hline N & Valid & 68 \\
\cline { 2 - 3 } & Missing & 0 \\
\hline Mean & 48.47 \\
\hline Std. Deviation & 8.892 \\
\hline Minimum & 33 \\
\hline Maximum & 69 \\
\hline Sum & 3296 \\
\hline
\end{tabular}

Agar mudah dibaca dan untuk menggambarkan frekuensi skor data hasil penelitian dari variabel Disiplin Dosen $\left(\mathrm{X}_{1}\right)$, dapat disajikan dalam bentuk histogram sebagai berikut:

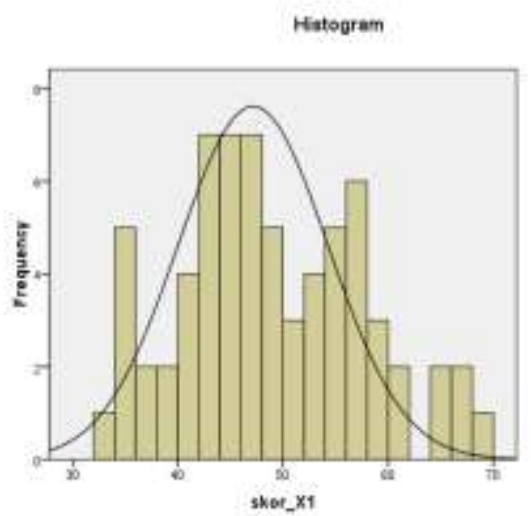

Gambar 4.1 Histrogram distribusi frekuensi skor variabel Disiplin Dosen $\left(\mathrm{X}_{1}\right)$

\section{Variabel Kompetensi Dosen $\left(\mathbf{X}_{2}\right)$}

Berdasarkan hasil pengumpulan data melalui kuesioner, variabel Kompetensi Dosen $\left(\mathrm{X}_{2}\right)$ memiliki olahan statistik sebagai berikut:

Tabel $4.2 \quad$ Statistik Variabel Kompetensi Dosen $\left(\mathrm{X}_{2}\right)$

\section{Statistics}

skor_X2

\begin{tabular}{|l|l|r|}
\hline N & Valid & 68 \\
\cline { 2 - 3 } & Missing & 0 \\
\hline Mean & 49.60 \\
\hline Std. Deviation & 10.137 \\
\hline Minimum & 32 \\
\hline Maximum & 75 \\
\hline Sum & 3373 \\
\hline
\end{tabular}

Agar mudah dibaca dan untuk menggambarkan frekuensi skor data 
hasil penelitian dari variabel variabel Kompetensi Dosen $\left(\mathrm{X}_{2}\right)$, dapat disajikan dalam bentuk histogram sebagai berikut :
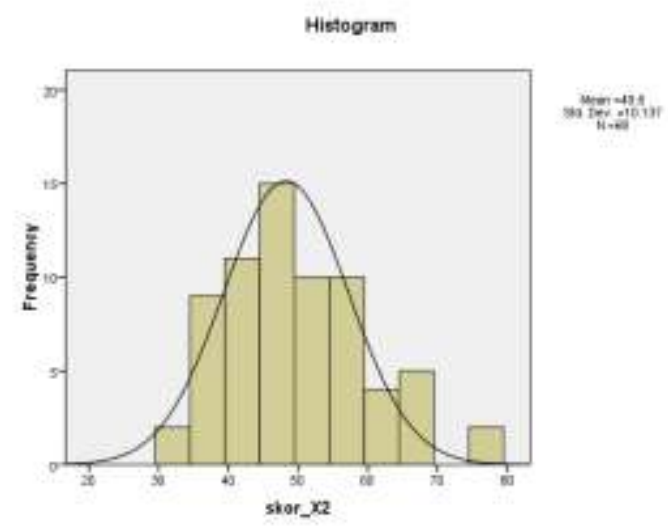

Gambar 4.2 Histrogram distribusi frekuensi skor variabel Kompetensi Dosen $\left(\mathrm{X}_{2}\right)$

\section{Prestasi Mahasiswa (Y)}

Berdasarkan hasil pengumpulan data melalui kuesioner, variabel Prestasi Mahasiswa(Y) yang merupakan variabel terikat memiliki olahan statistik sebagai berikut:

Tabel 4.3 Statistik Variabel Prestasi Mahasiswa (Y)

Statistics

skor_Y
\begin{tabular}{|l|l|r|}
\hline N & Valid & 68 \\
\cline { 2 - 3 } & Missing & 0 \\
\hline Mean & 51.93 \\
\hline Std. Deviation & 8.038 \\
\hline Minimum & 36 \\
\hline Maximum & 70 \\
\hline Sum & 3531 \\
\hline
\end{tabular}

Agar mudah dibaca dan untuk menggambarkan frekuensi skor data hasil penelitian dari variabel Prestasi Mahasiswa (Y), dapat disajikan dalam bentuk histogram sebagai berikut:

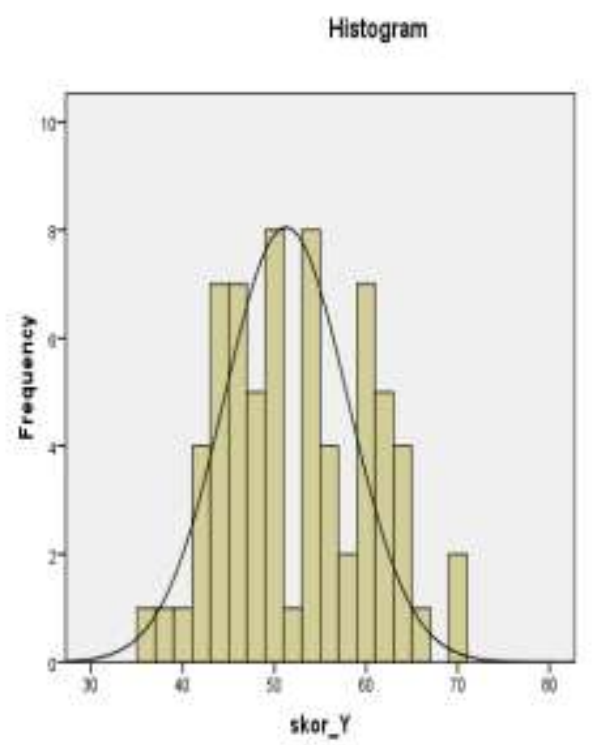

Gambar 4.3

Histrogram distribusi frekwensi skor variabel Prestasi Mahasiswa (Y)

Pengaruh Disiplin Dosen $\left(\mathbf{X}_{1}\right)$ terhadap Prestasi Mahasiswa (Y)

Untuk mengetahui apakah ada pengaruh Disiplin Dosen $\left(\mathrm{X}_{1}\right)$ terhadap Prestasi Mahasiswa (Y), maka digunakan analisis regresi sederhana. Analisis data dilakukan dengan menggunakan bantuan software SPSS for Windows Versi 17.0. Dari hasil analisis data, diperoleh nilai konstan $\left(a_{1}\right)$ dan nilai koefisien regresi $\left(b_{1}\right)$ masing-masing adalah 18,789 dan 0,684seperti yang disajikan pada Tabel 4.14 berikut ini 
Tabel 4.14

Koefisien Regresi ( $\mathrm{X}_{1}$ terhadap $\mathrm{Y}$ )

Coefficients $^{\mathrm{a}}$

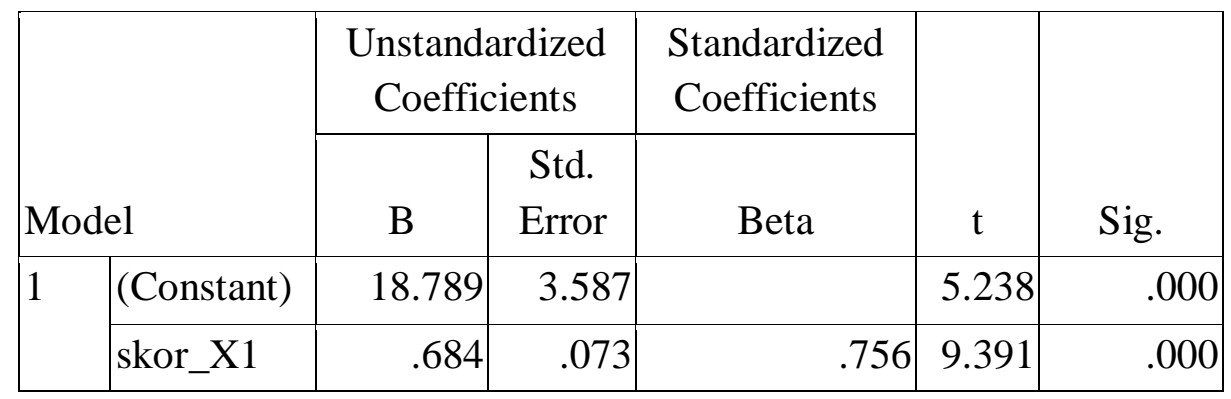

a. Dependent Variable: skor_Y

Dengan demikian persamaan regresinya adalah, $\mathrm{Y}=18,789+0,684$ $\mathrm{X}_{1}$. Secara grafis persamaan regresi ini dapat dilihat pada Gambar 4.4 sebagai berikut:

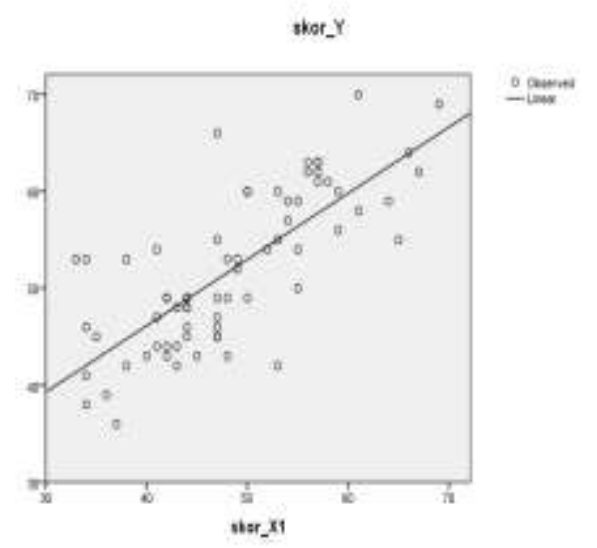

Gambar 4.4 Pengaruh $\mathrm{X}_{1}$ terhadap $\mathrm{Y}$

Harga-harga tersebut dapat diinterpretasikan sebagai berikut:

a. Nilai $\mathrm{a}=18,789$ adalah bilangan konstan, artinya apabila nilai Disiplin Dosen diabaikan, maka Prestasi Mahasiswa nilainya $18,789$.

b. Nilai $b_{1}=0,684$ adalah nilai koefisien regresi, artinya setiap ada kenaikan nilai Disiplin Dosen sebesar 1 (satu) unit, maka akan meningkatkan nilai Prestasi Mahasiswa sebesar 0,684 unit.

Untuk membuktikan apakah koefisien regresi Disiplin Dosen tersebut cukup signifikan atau tidak dilakukan uji signifikansi melalui uji t pada taraf $1 \%$. Jika nilai $t_{\text {hitung }}>$ $\mathrm{t}_{\text {tabel}}$, maka ada pengaruh yang signifikan dan jika $t_{\text {hitung }}<t_{\text {tabel }}$, maka tidak ada pengaruh. Nilai $t_{\text {tabel }}$ pada taraf signifikan $1 \%$ dengan $\mathrm{db}=66$ adalah 2,384.

Berdasarkan yang terlihat pada Tabel 4-14, koefisien regresi didapatkan $\quad t_{\text {hitung }}=9.391$. Selanjutnya harga $t_{\text {hitung }}$ ini dibandingkan dengan nilai $t_{\text {tabel }}$. Ternyata nilai $t_{\text {hitung }}$ lebih besar dari nilai $t_{\text {tabel }}(9.391>2,384)$, artinya $\mathrm{H}_{0}$ ditolak dan $\mathrm{H}_{1}$ diterima. Dengan demikian Disiplin Dosen berpengaruh secara signifikan terhadap Prestasi Mahasiswa dengan keabsahan sebesar 99\%. (Hipotesis 1 terbukti)

Setelah persamaan regresi diketemukan maka langkah selanjutnya adalah menghitung besarnya koefisien determinan $\left(\mathrm{R}^{2}\right)$. 
Koefisien deteminan $\left(\mathrm{R}^{2}\right)$ ini bentuk persen. Berdasarkan output menunjukkan seberapa besar SPSS besarnya koefisien determinan pengaruh variabel Disiplin Dosen adalah 0,572 seperti yang disajikan terhadap Prestasi Mahasiswa dalam pada Tabel 4.15 berikut ini:

Tabel 4.15 Koefisien Determinan (R Square) $\mathrm{X}_{1}$ terhadap $\mathrm{Y}$

Model Summary

\begin{tabular}{|l|l|r|r|r|}
\hline $\begin{array}{l}\text { Mod } \\
\text { el }\end{array}$ & $\mathrm{R}$ & $\begin{array}{c}\mathrm{R} \\
\text { Square }\end{array}$ & $\begin{array}{c}\text { Adjusted R } \\
\text { Square }\end{array}$ & $\begin{array}{c}\text { Std. Error } \\
\text { of the } \\
\text { Estimate }\end{array}$ \\
\hline 1 & $.756^{\mathrm{a}}$ & .572 & .565 & 5.298 \\
\hline
\end{tabular}

a. Predictors: (Constant), skor_X1

Nilai $\mathrm{R}^{2}$ tersebut menunjukkan bahwa variabel Disiplin Dosen memberikan pengaruh terhadap variabel Prestasi Mahasiswa sebesar 57,2\%, sedangkan sisanya sebesar $42,8 \%$ ditentukan oleh faktor lain yang belum diketahui/tidak masuk dalam model penelitian.

\section{Pengaruh Kompetensi Dosen $\left(\mathrm{X}_{2}\right)$ terhadap Prestasi Mahasiswa (Y)}

Untuk mengetahui apakah ada pengaruh Kompetensi Dosen terhadap Prestasi Mahasiswa, maka digunakan analisis regresi sederhana. Analisis data dilakukan dengan menggunakan bantuan komputer software SPSS for Windows versi
17.0. Dari hasil analisis data dengan menggunakan bantuan komputer, diperoleh nilai konstan $\left(\mathrm{a}_{2}\right)$ dan nilai koefisien regresi $\left(b_{2}\right)$ masing-masing adalah 22,911 dan 0,585 seperti yang terlihat pada Tabel 4.16 berikut ini :

Tabel 4.16

Koefisien Regresi ( $\mathrm{X}_{2}$ terhadap Y)

Coefficients $^{\mathrm{a}}$

\begin{tabular}{|c|c|c|c|c|c|}
\hline \multirow[b]{2}{*}{ Model } & \multicolumn{2}{|c|}{$\begin{array}{l}\text { Unstandardized } \\
\text { Coefficients }\end{array}$} & \multirow{2}{*}{$\begin{array}{c}\text { Standardized } \\
\text { Coefficients } \\
\text { Beta }\end{array}$} & \multirow[b]{2}{*}{$\mathrm{t}$} & \multirow[b]{2}{*}{ Sig. } \\
\hline & B & $\begin{array}{l}\text { Std. } \\
\text { Error }\end{array}$ & & & \\
\hline \begin{tabular}{l|l}
1 & $\begin{array}{l}\text { Consta } \\
\text { nt })\end{array}$
\end{tabular} & 22.911 & 3.335 & & 6.869 & .000 \\
\hline \begin{tabular}{|l|} 
skor_X \\
2
\end{tabular} & .585 & .066 & .738 & 8.877 & .000 \\
\hline
\end{tabular}

a. Dependent Variable: skor_Y 
Dengan demikian persamaan regresinya adalah $\mathrm{Y}=22,911+0,585 \mathrm{X}_{2}$, seperti yang disajikan pada Gambar 4-5 di bawah berikut ini.

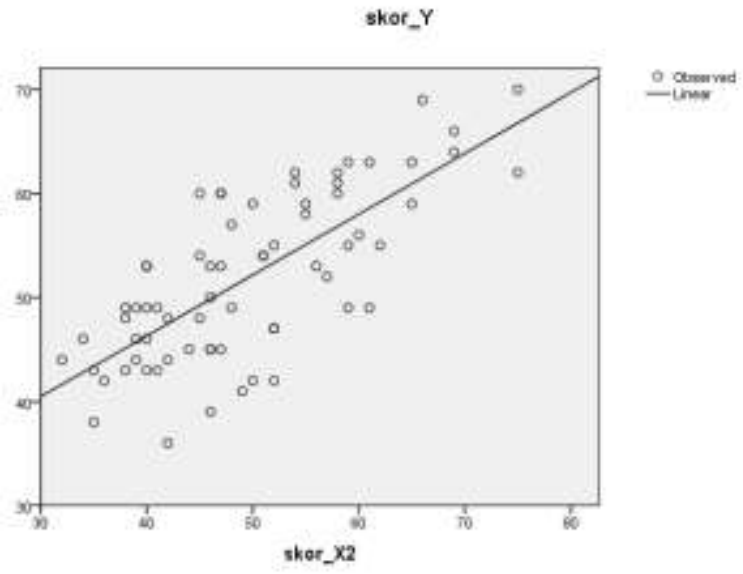

Gambar 4.5

Pengaruh Kompetensi Dosen terhadap Prestasi Mahasiswa

Angka-angka tersebut dapat diinterpretasikan sebagai berikut:

$\circ \mathrm{a}=22,911$ adalah bilangan konstan, artinya apabila nilai Kompetensi Dosen diabaikan, maka Prestasi Mahasiswa nilainya 22,911

$\circ \mathrm{b}_{2}=0,585$; adalah nilai koefisien regresi, artinya setiap ada kenaikan nilai Kompetensi Dosen sebesar 1 (satu) unit, maka akan meningkatkan nilai Prestasi Mahasiswa sebesar 0,585unit.

Untuk membuktikan apakah koefisien regresi Kompetensi Dosen tersebut cukup signifikan atau tidak dilakukan uji signifikansi melalui uji t pada taraf $1 \%$. Jika nilai $t_{\text {hitung }}>$ $\mathrm{t}_{\text {tabel}}$, maka ada pengaruh yang signifikan dan jika nilai $\mathrm{t}_{\text {hitung }}<\mathrm{t}_{\text {tabel}}$, maka tidak ada pengaruh yang signifikan. Nilai $t_{\text {tabel }}$ pada taraf signifikan $1 \% \mathrm{db}=66$ adalah 2,384 .
Berdasarkan nilai koefisien regresi seperti yang ditunjukkan pada Tabel 4.16, nilai $t_{\text {hitung }}$ adalah sebesar 8.877. Selanjutnya $t_{\text {hitung }}$ ini dibandingkan dengan nilai $t_{\text {tabel }}$. Ternyata nilai $\mathrm{t}_{\text {hitung }}$ lebih besar dari nilai $t_{\text {tabel }}(8.877>2,384)$, artinya $\mathrm{H}_{0}$ ditolak dan $\mathrm{H}_{1}$ diterima. Dengan demikian Kompetensi Dosen berpengaruh secara signifikan terhadap Prestasi Mahasiswa dengan ketelitian 99\%.(Hipotesis 2 terbukti)

Setelah persamaan regresi diketemukan maka langkah selanjutnya adalah menghitung besarnya koefisien determinan $\left(\mathrm{R}^{2}\right)$. Koefisien deteminan menunjukkan seberapa besar pengaruh variabel Kompetensi Dosen terhadap Prestasi Mahasiswa dalam bentuk prosen. Berdasarkan output SPSS besarnya koefisien determinan seperti yang disajikan pada Tabel 4-17 adalah 0,544 . 


$\begin{array}{llll}\text { Nilai } & \text { tersebut membuktikan } & \text { sedangkan sisanya sebesar } 45,6 \% \\ \text { bahwa } & \text { Kompetensi } & \text { Dosen } & \text { ditentukan oleh faktor lain yang tidak } \\ \text { mememberikan pengaruh terhadap } & \text { masuk dalam model penelitian ini. }\end{array}$

Tabel 4.17

Koefisien Determinan (R Square) $\mathrm{X}_{2}$ terhadap $\mathrm{Y}$

Model Summary

\begin{tabular}{|l|l|r|r|r|}
\hline Model & $\mathrm{R}$ & \multicolumn{1}{c|}{$\mathrm{R}$} & \multicolumn{1}{c|}{$\begin{array}{c}\text { Adjusted R } \\
\text { Square }\end{array}$} & $\begin{array}{c}\text { Std. Error } \\
\text { of the } \\
\text { Estimate }\end{array}$ \\
\hline 1 & $.738^{\mathrm{a}}$ & .544 & .537 & 5.468 \\
\hline
\end{tabular}

a. Predictors: (Constant), skor_X2

\section{Pengaruh Disiplin Dosen $\left(\mathrm{X}_{1}\right)$ dan Kompetensi Dosen $\left(\mathrm{X}_{2}\right)$ secara bersama- sama terhadap Prestasi Mahasiswa (Y)}

Untuk mengetahui adanya pengaruh Disiplin Dosen dan Kompetensi Dosen secara bersamasama terhadap Prestasi Mahasiswa digunakan analisis regresi berganda. Analisis data dilakukan dengan menggunakan bantuan SPSS for
Windows versi 17.0, dan diperoleh nilai-nilai sebagai berikut:

$$
\begin{aligned}
& a=16,367 \\
& b_{1}=0,419 \text { dan } \\
& b_{2}=0,307, \text { seperti pada tabel di bawah } \\
& \text { ini: }
\end{aligned}
$$

Tabel 4.18 Koefisien Regresi Ganda $\left(\mathrm{X}_{1}\right.$, dan $\mathrm{X}_{2}$ terhadap $\left.\mathrm{Y}\right)$

\section{Coefficients $^{\mathrm{a}}$}

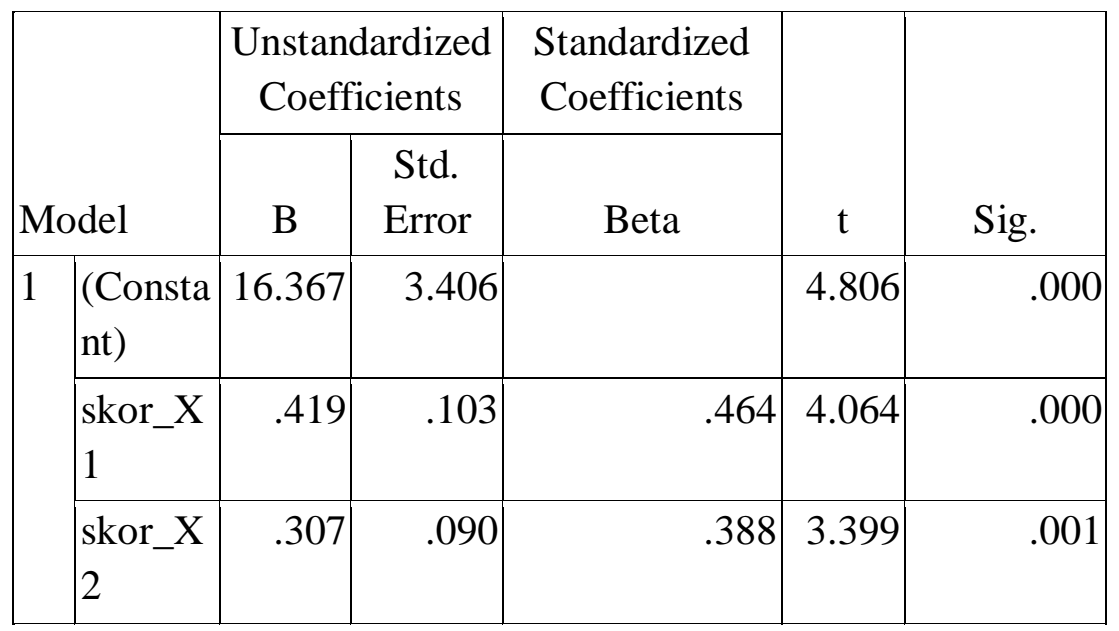

a. Dependent Variable: skor_Y 
Pengaruh Disiplin Dosen dan Kompetensi Dosen secara bersamasama terhadap Prestasi Mahasiswa dapat dinyatakan sebagai berikut :

$\mathrm{Y}=16,367+0,419 \mathrm{X}_{1}+0,307 \mathrm{X}_{2}$

Nilai konstanta dan regresi dalam persamaan regresi ganda tersebut dapat diinterpretasikan sebagai berikut :

$\circ \mathrm{a}=16,367$; adalah bilangan konstan menunjukkan nilai Prestasi Mahasiswa , jika Disiplin Dosen dan Kompetensi Dosennilainya dianggap sama dengan nol

$\circ b_{1}=0,419$; adalah nilai koefisien regresi $b_{1}, \quad$ artinya setiap kenaikan/penambahan nilai Disiplin Dosen sebesar satu unit akan meningkatkan nilai Prestasi Mahasiswa sebesar 0,419 unit. $\circ \mathrm{b}_{2}=0,307$ adalah nilai koefisien regresi $b_{2}, \quad$ artinya setiap kenaikan/penambahan nilai Kompetensi Dosen sebesar satu unit akan meningkatkan nilai Prestasi Mahasiswa sebesar 0,307 unit.

Untuk membuktikan apakah pengaruh tersebut cukup signifikan atau tidak, dilakukan uji hipotesis (uji signifikansi) melalui uji $\mathrm{F}$ pada taraf 5\%, dengan ketentuan jika nilai $\mathrm{F}_{\text {hitung }}>\mathrm{F}_{\text {tabel }}$, maka $\mathrm{H}_{0}$ ditolak dan $\mathrm{H}_{1}$ diterima, sebaliknya jika nilai $F_{\text {hitung }}$ $<\mathrm{F}_{\text {tabel}}$, maka $\mathrm{H}_{0}$ diterima dan $\mathrm{H}_{1}$ ditolak. Nilai $F_{\text {tabel }}$ pada taraf signifikan $5 \%$ dengan db pembilang 2 dan db penyebut 65 adalah 3,138 . Besarnya nilai $F_{\text {hitung }}$ dapat dilihat tabel Anova di bawah ini:

Tabel 4.19

Tabel Anova pengaruh $\mathrm{X}_{1}$ dan $\mathrm{X}_{2}$ terhadap $\mathrm{Y}$

ANOVA $^{b}$

\begin{tabular}{|c|c|c|c|c|c|c|}
\hline \multicolumn{2}{|c|}{ Model } & \multirow{2}{*}{$\begin{array}{l}\begin{array}{l}\text { Sum of } \\
\text { Squares }\end{array} \\
2755.452\end{array}$} & \multirow{2}{*}{\begin{tabular}{r|} 
df \\
2
\end{tabular}} & \multirow{2}{*}{\begin{tabular}{|r|} 
Mean Square \\
1377.726
\end{tabular}} & \multirow{2}{*}{$\frac{F}{56.924}$} & \multirow{2}{*}{$\begin{array}{l}\text { Sig. } \\
.000\end{array}$} \\
\hline 1 & $\begin{array}{l}\text { Regressio } \\
\mathrm{n}\end{array}$ & & & & & \\
\hline & Residual & 1573.180 & 65 & 24.203 & & \\
\hline & Total & 4328.632 & 67 & & & \\
\hline
\end{tabular}

a. Predictors: (Constant), skor_X2, skor_X1

b. Dependent Variable: skor_Y

Ternyata nilai $F_{\text {hitung }}$ lebih besar dari nilai $\mathrm{F}_{\text {tabel }}(56.924>3,138)$, artinya $H_{0}$ ditolak dan $H_{1}$ diterima. Dengan demikian variabel Disiplin Dosen dan Kompetensi Dosen secara bersama-sama mempunyai pengaruh yang signifikan terhadap variabel Prestasi Mahasiswa, dengan ketelitian 95\%. (Hipotesis 3 terbukti). 


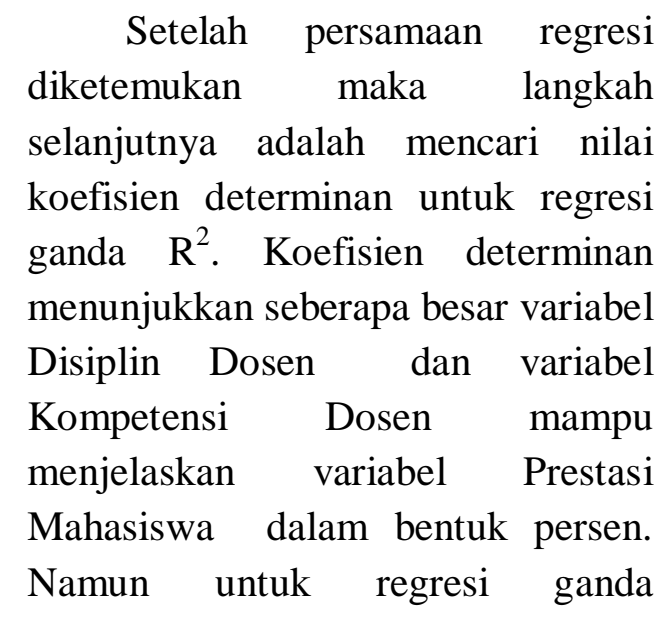

sebaiknya menggunakan $\mathrm{R}^{2}$ yang sudah disesuaikan atau tertulis Adjusted $\boldsymbol{R}$ Square, karena telah disesuaikan dengan jumlah variabel independen yang digunakan dalam penelitian.

Berdasarkan output SPSS besarnya nilai koefisien determinan yang sudah disesuaikan (Adjusted $\mathrm{R}$ Square) adalah 0,625, seperti yang terlihat dalam tabel berikut ini :

Tabel 4.20 Adjusted R Square $\mathrm{X}_{1}$, dan $\mathrm{X}_{2}$, terhadap Y

Model Summary

\begin{tabular}{|l|c|r|r|r|}
\hline Model & $\mathrm{R}$ & $\begin{array}{c}\mathrm{R} \\
\text { Square }\end{array}$ & $\begin{array}{c}\text { Adjusted R } \\
\text { Square }\end{array}$ & $\begin{array}{l}\text { Std. Error of } \\
\text { the Estimate }\end{array}$ \\
\hline 1 & $.798^{\mathrm{a}}$ & .637 & .625 & 4.920 \\
\hline
\end{tabular}

a. Predictors: (Constant), skor_X2, skor_X1

Nilai tersebut membuktikan bahwa variabel Disiplin Dosen dan variabel Kompetensi Dosen secara bersama-sama berpengaruh terhadap variabel Prestasi Mahasiswa sebesar $62,5 \%$. sedangkan sisanya sebesar $37,5 \%$ ditentukan oleh faktor lain yang tidak masuk dalam model penelitian ini.

\section{Pembahasan}

Berdasarkan hasil pengujian pertama, menggambarkan bahwa terdapat pengaruh yang positif dan signifikan antara kedisiplinan dosen dengan prestasi mahasiswa. Hal itu didasarkan pada aspek-aspek yang berimplikasi dalam mendorong sikap mental individu disiplin yaitu etika, moral, dan sikap perilaku.

James A.F. Stoner (1994: 158) mengatakan bahwa etika adalah telaah mengenai hak dan kewajiban orang, kaidah moral yang diterapkan mengambil keputusan-keputusan dan sifat dari hubungan antar orangorang.

Memperhatikan uraian tersebut, dapat dikemukakan bahwa sikap atau mentalitas disiplin itu searah atau tidak searahnya perbuatan seseorang dengan hati nuraninya. Nilai dari sikap dan perilaku disiplin dalam banyak hal ditentukan oleh sesuai atau tidaknya seseorang menepati janji atau menyelesaikan tugas pada waktunya.

Dengan demikian, dapat disimpulkan bahwa perilaku disiplin dosen sangat penting untuk dipelihara dalam pendidikan sebab perilaku disiplin dosen sangat menentukan mentalitas mahasiswa menjadi lebih baik, antara lain 
menjadi individu yang rajin, jujur, berani, bersungguh-sungguh, penuh percaya diri, tahu malu, berkemauan keras, bercita-cita, menyukai kebersihan, dan memiliki kepedulian yang merupakan satu kesatuan utuh dari disiplin. Hal tersebut sesuai seperti yang dinyatakan Nitisemito (2001) seperti yang terdapat pada tabel berikut ini.

\begin{tabular}{ll}
\hline \multicolumn{1}{c}{ Dimensi } & \multicolumn{1}{c}{ Indikator } \\
\hline Kesadaran dosen & 1. Hadir tepat waktu \\
& 2. Pulang tepat waktu \\
& 3. Tugas dan tanggung jawab \\
& 4. Sikap baik dalam bekerja \\
\hline Kesediaan dalam bekerja & 1. Tingkah laku dosen \\
& 2. Perbuatan yang baik \\
& 3. Pengabdian \\
\hline Sikap dosen & 1. Kesetiaan \\
& 2. Peka pada lingkungan kerja \\
& 3. Persamaan dan kesetaraan \\
& 4. Keteladanan pimpinan \\
& 5. Keadilan \\
& 6. Ketegasan pimpinan \\
\hline Ketaatan dalam melaksanakan tugas & 1. Taat pada ketentuan \\
& 2. Sanksi hukuman \\
\hline
\end{tabular}

Berdasarkan hasil pengujian kedua, kompetensi dosen berpengaruh positif dan signifikan terhadap prestasi mahasiswa. Pembuktian itu relevan dengan karakteristik individu berkompeten yang disampaikan (Ruky, 2003: 16) yaitu sumber daya manusia yang kompeten ialah yang mempunyai ciri-ciri sebagai berikut:

a. Memiliki pengetahuan penuh tentang tugas, tanggung jawab, dan wewenang.

b. Memiliki pengetahuan (knowledge) yang diperlukan terkait dengan pelaksanaan tugas secara penuh. c. Mampu melaksanakan tugastugas yang harus dilakukannya karena mempunyai keahlian atau keterampilan (skill) yang diperlukan.

d. Bersikap produktif, inovatif atau kreatif, mau bekerja sama dengan orang lain, dapat dipercaya, dan loyal.

Ciri-ciri individu kompeten yang dinyatakan Ruki tersebut sesuai dengan instrumen yang digunakan dalam penelitian ini yang merujuk pada Prihadi (2004) bahwa dimensi perilaku dosen terletak di balik kinerjanya yang kompeten meliputi efektivitas dan efisiensi. Definisi ini mengandung deskripsi perilaku, 
sikap, dan karakteristik orang dalam melakukan berbagai tugas untuk menghasilkan output yang efektif.
Dimensi perilaku kompeten yang dinyatakan Prihadi seperti yang terdapat pada tabel berikut ini.

\begin{tabular}{ll}
\hline \multicolumn{1}{c}{ Dimensi } & \multicolumn{1}{c}{ Indikator } \\
\hline & 1. Pengendalian emosi \\
a. Trait (Karateristik) & 2. Kondisi \\
& 3. Kemampuan analitikal \\
& 4. Ketajaman naluri \\
\hline & 1.Menerima pendapat orang lain \\
b. Flexibility (Fleksibilitas) & 2.Pengembangan organisasi \\
& 3.Pengembangan individu \\
\hline & 1. Jaringan komunikasi \\
& 2. Rotasi pegawai \\
c. Skill (Kemampuan) & 3. Prestasi kerja \\
& 4. Motivator \\
\hline & 5. Wawasan yang luas \\
d. Knowledge (Pengetahuan) & 6.Kemampuan menduduki jabatan \\
& 7. Diklat dosen \\
\hline
\end{tabular}

Berdasarkan hasil pengujian ketiga, disiplin dan kompetensi dosen berpengaruh positif dan signifikan terhadap prestasi mahasiswa. Temuan ini relevan dengan pernyataan Suprihanto (2000) yang memetakan dimensi prestasi mahasiswa sebagai berikut.

\begin{tabular}{ll}
\hline \multicolumn{1}{c}{ Dimensi } & \multicolumn{1}{c}{ Indikator } \\
\hline Hasil yang dicapai & 1. Mutu mahasiswa \\
& $\begin{array}{l}\text { 2. Pengembangan } \\
\text { mahasiswa }\end{array}$ \\
& 3. Pengetahuan mahasiswa \\
& 4. Hasil kerja mahasiswa \\
\hline Produktivitas & 1. Efektivitas \\
Mahasiswa & 2. Disiplin \\
& 3. Loyalitas \\
& 4. Strategi \\
& 5. Semangat \\
\hline
\end{tabular}

Dimensi hasil yang dicapai dan produktivitas mahasiswa itu relevan dengan pernyataan Mangkunegara
(2000), Hasibuan (2005), dan Sastrohadiwiryo (2002) yang menyatakan bahwa prestasi 
akademik mahasiswa merupakan hasil kerja keras yang mengandung kualitas dan kuantitas pencapaian seseorang dalam menjalankan tugas yang dibebankan kepadanya sesuai dengan tanggung jawab peserta didik.

Untuk mencapai prestasi akademis yang baik, unsur yang paling dominan adalah sumber daya manusia, walaupun perencanaan telah tersusun dengan baik dan rapi tetapi apabila dosen yang melaksanakan tidak berkualitas dan tidak memiliki semangat kerja yang tinggi, maka perencanaan yang telah disusun mahasiswa tidak akan berjalan secara maksimal.

Dari analisis di atas dapat disimpulkan bahwa terdapat pengaruh disiplin dan kompetensi dosen baik secara sendiri maupun bersama-sama terhadap prestasi mahasiswa di program studi Penerbitan Politeknik Negeri Media Kreatif Jakarta.

\section{PENUTUP}

Penelitian menyimpulkan bahwa terdapat pengaruh positif dan signifikan antara kedisiplinan dan kompetensi dosen dengan prestasi mahasiswa, baik secara sendirisendiri maupun secara bersamasama. Artinya, akan meningkat prestasi mahasiswa jika kedisiplinan dan kompetensi dosen ditingkatkan. Dengan demikian, secara umum prestasi mahasiswa, dipengaruhi langsung secara positif dan signifikan oleh kedisiplinan dan kompetensi dosen.
Implikasi manajerial yang harus dilakukan adalah memberi perhatian kepada kedua variabel yakni kedisiplinan dan kompetensi dosen secara bersama-sama terhadap prestasi mahasiswa program studi Penerbitan di Politeknik Negeri Media Kreatif Jakarta.

\section{DAFTAR RUJUKAN}

Hasibuan, Malayu S.P. 2007. Organisasi dan Motivasi Dasar Peningkatan Produktivitas. Jakarta: Bumi Aksara.

Hornby dan Thomas (Prihadi, 2004:

89). Assesment Centre: Identifikasi, Pengukuran dan Pengembangan Kedisiplinan Dosen. Jakarta: PT Gramedia Pustaka Utama.

James, A.F., Stoner. 2001. Manajemen. Jakarta: Penerbit Intermedia.

Lucia dan Lepsiger (Prihadi, 2004). Assesment Centre: Identifikasi, Pengukuran dan Pengembangan Kedisiplinan Dosen. Jakarta: PT Gramedia Pustaka Utama.

Mangkunegara, A.A., Anwar Prabu. 2000. Manajemen Sumber Daya Manusia. Bandung: PT Remaja Rosdakarya.

Mathis dan Jackson. 2002. Manajemen Sumber Daya Manusia. Yogyakarta: Penerbit Salemba.

Nitisemito, A.S. 2001. Manajemen Personalia. Jakarta: Ghalia Indonesia. 
Jurnal Publipreneur, Vol. 2, Nomor 4, Desember 2014, ISSN: 2338-5049

Ruky, A.S. 2003. Manajemen

Penggajian dan Pengupahan

Karyawan Perusahaan.

Jakarta: PT Gramedia Pustaka

Utama.
Sastrohadiwiryo, Siswanto. 2002. Manajemen Tenaga Kerja

Indonesia. Jakarta: Bumi

Aksara. 